Accepted in Quaternary Intenational April 2006

\title{
From natural hazard to environmental catastrophe: Past and present
}

\author{
Suzanne A. G. Leroy \\ Institute for the Environment, Brunel University, Uxbridge UB8 3Ph (West \\ London), UK \\ Fax: 44-1895-269 736, suzanne.leroy@brunel.ac.uk
}

\begin{abstract}
The number of environmental catastrophes is rising, mostly owing to an increase in hydrometeorological hazards. The number of disasters is escalating as the world population grows and people settle in marginal areas. In order to improve preparedness, the geological and archaeological records must be investigated as they hold a wider range of possible events than the much shorter instrumental record. Catastrophes will gain amplitude with rapid onset, long duration, larger affected area, inflexible society and, of cause, convergence of threats. Too often, it seems that today's societies resist learning from the past and therefore tend to repeat errors. A new field of science is emerging: the science of environmental catastrophes, which requires not only robust chronologies to firmly link cause and effect, but also bridges the crossing between the geosciences and social sciences.
\end{abstract}

\section{Key words}

Environmental catastrophe, Holocene, civilisation collapse, natural hazard, societal response

\section{Introduction}

Natural hazards are an integral component of life on Earth (ICSU, 2005). The number of recorded natural hazards has increased in the last fifty years with the greatest increase in frequency attributed to hydrometeorological disasters, with a lesser increase attributed to biological disasters and a slightly lesser increase attributed to geological disasters (ICSU, 2005). Moreover, the number of natural hazards culminating in disasters also has tremendously increased. Natural disasters were especially prolific in 2005 following the Indian Ocean tsunami (December 2004), often occurring at catastrophic levels (e.g. the Pakistan/India earthquake and Hurricane Katrina over the US Gulf Coast). Quite timely, international interest in the geological and archaeological fields has focussed since 2002 on the theme of rapid and catastrophic environmental changes and human and ecosystem responses occurring in the last millennia.

In this paper I aim to present the results of a series of scientific meetings where various challenges and questions are discussed, especially concerning the record of ancient catastrophes, need to work in multidisciplinary teams, time resolution with geological and archaeological data, relevance to modern societies, and new forces that can help humans adapt in order to prevent civilisations from collapsing. After an initial meeting at Brunel University (West London, UK) in 2002 (Leroy and Stewart, 2002), international scientific 
societies have provided support to further discuss these topics in the framework of the International Geological Correlation Program 490 (IGCP 490, 2006) and the International Council of Sciences (ICSU, 2006) Dark Nature conference project in 2004 and 2005 with meetings in Mauritania (Leroy and Costa, 2004; Leroy et al., 2006 a and b), Mozambique, Argentina (Piovano et al., in prep.), Iran, Canada and Italy (Michetti et al., 2005) (all abstracts available at ICSU, 2006). Humans also cause environmental catastrophes, but this is not the theme of this research, which only serves to examine natural events.

\section{What constitutes an environmental catastrophe?}

According to the ICSU, for the period 1994-2003, floods represented $33 \%$ of the natural hazards, storms $23 \%$, epidemics $15.2 \%$, droughts $15 \%$, earthquakes $7 \%$, tsunamis $7 \%$, landslides $4.5 \%$ and volcanic eruptions 1.4 $\%$, whereas avalanches accounted only for $0.7 \%$ of the total number of events (ICSU, 2005). Hazards related to extreme weather conditions occurred most frequently and often affected the largest areas. Most of these events lead to disasters but did not led necessarily to environmental catastrophes.

\subsection{Definitions and non-linearity in societal responses}

We could attempt to define an environmental catastrophe, such as a natural hazard combined with a large disaster, the latter including measurable human and economical costs (e.g. death, infrastructure destruction, cultural impact, financial loss). In its definition of natural disaster, the International Human Dimension Programme (IHDP) stresses that it is more a function of vulnerable people than severity in the natural hazard (Lonergan et al., 1999). An environmental catastrophe also could be defined as a rapid departure from normality where humans and/or ecosystems cannot adapt. However, catastrophic events do not always occur rapidly. In addition, these events may be, in some cases, more pervasive at the societal scale and, retrospectively, seen as catastrophes. At times, it is difficult to separate catastrophes from "normal" environmental events, since the environment is never stable, but always undergoing modification: "Not nature in balance, but nature in flux" (Berger, 2006).

A large cause (environmental hazard) may produce only a small effect (disaster) and vice versa. Societal responses to external forces are non-linear in nature; hence, in the geoarchaeological record, assumption of causality between cultural transition and natural hazard often is questionable (Coombes and Barber, 2005) and must be used with care.

\subsection{Combination of factors}

The three factors contributing to the amplitude of an environmental catastrophe include time, area and societal characteristics (Figure 1). 


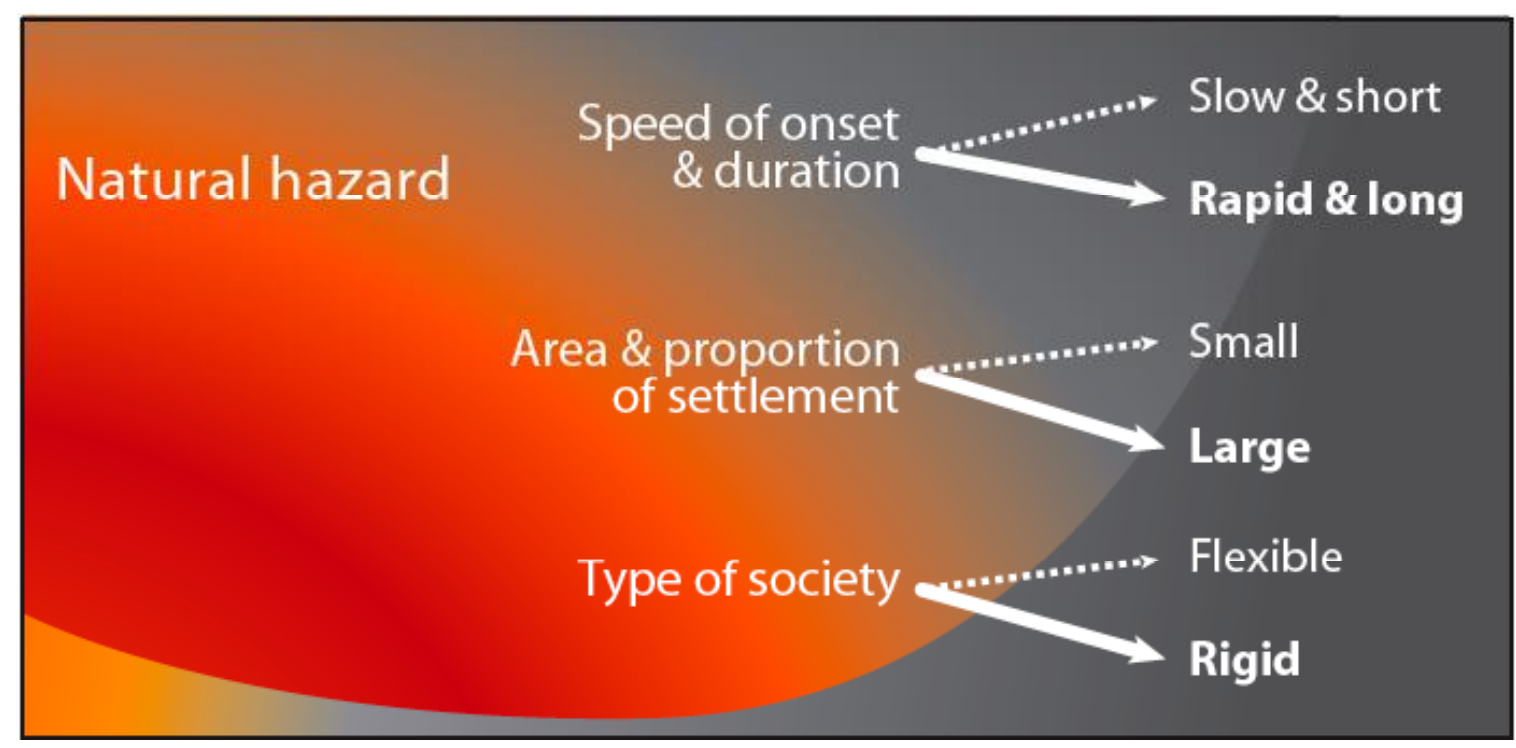

Figure 1: A catastrophe results from the combination of time, area and societal characteristics

\subsubsection{Onset rapidity and duration}

The time factor (sharp onset and overall duration) is an essential consideration in defining an environmental catastrophe (Figure 1). First, the usual high speed of change makes it impossible for humans to adapt unless preparedness plans are in place. Second, events of longer duration result in greater damage: for example an environmental change that extends beyond the food storage capacity of a society. Recent estimates indicate the global supply of grains, if not replenished, would last barely two months (Rampino, 2005). After a nuclear war or volcanic winter, it has "emerged that the main cause of disaster would be destruction of global agriculture and food supply" (Sparks, Self et al., 2005). "After a year of severely reduced food supply, there would be mass starvation. Because a nuclear [or volcanic] winter might last two or three years, scientists concluded that this would threaten the continued existence of civilisation (and possibly even our species)" (Sparks, Self et al., 2005).

\subsubsection{Area}

An environmental catastrophe affecting a large area (typical of a drought), or a large proportion of a settlement, will be more difficult to overcome than one affecting a smaller area (typical of a flood, earthquake, volcanic eruption) (Figure 1). People living in these areas must move further away to survive, but, most often, they have nowhere to go to escape the disaster. Of course, this predicament is exacerbated on small islands (e.g. Easter Island) and on densely populated continental areas. In terms of anthropological studies, some pronounced cultural changes have been connected to disasters encompassing large areas (Torrence and Grattan, 2002).

\subsubsection{Type of society or ecosystem}

A flexible society and/or ecosystem will be able to adapt faster to environmental changes and thus suffer less (Figure 1). Societies can increase their inflexibility under conditions such as fixed hierarchies where one person 
cannot replace another, fixed religious rules that impose proscriptions, food prohibitions, fewer personal freedoms (e. g. to pursue innovative or parallel thinking), or tendencies to reject or despise other ways of life. For example, the Norse settlements in Greenland collapsed for various reasons. Because they despised the Inuit people, the Norsemen were hindered in learning how to survive in Arctic conditions by using skin boats, harpoons for hunting ring seal at sea and multilayered skin clothing (Diamond, 2005).

\subsection{Convergence of threats}

A single landslide or earthquake usually will not lead to the collapse of a civilisation. However, earthquake storms or clusters, such as occurred at AD 365 in the eastern Mediterranean area (Stiros, 2001; Ambraseys et al., 1991), could have had the capacity for major impacts resulting in collapse of a civilisation. The effects of such single natural disasters can be multiplied if inflicted on a society that already is stressed by other factors (such as a pervasive drought) that makes the society less resilient. For example, a succession of changes occurred in Anatolia and the Levant in the fourth to the sixth centuries (Heim et al., 1997; Leroy et al., 2002): earthquake storm, desertification, population movement, new religion, and shift from farming to pastoralism in many places.

In addition to strictly physical phenomena, social reasons cumulatively may cause societal collapse. The five major causes of societal collapse as seen by Diamond (2005), include environmental damage, climate change, hostile neighbours, loss of relation with friendly partners and cultural responses of the people. Of the various cases that he analysed, which included the Anasazi of Chaco Canyon at AD 1200, Easter Island at C. AD 1600 (Hunt and Lipo (2006) suggest after European contact), Classic Maya period at AD 900 and Norse colonies in Greenland at C. AD 1450, only the latter case encompasses the five factors.

\subsection{Measuring environmental catastrophes}

There is no absolute, or relative, scale for measuring environmental catastrophes. This scale would require combining the strength of a natural phenomenon with the impact of a disaster on a society or ecosystem. Where natural phenomena may often be quantified, the impacts of disasters are immeasurable except by determining the number of deaths (in 2005 the Pakistan/India earthquake ranks highest), price of a commodity such as oil, insured losses and economic losses (in 2005 Hurricane Katrina ranks highest for the latter two measures).

\section{Records of ancient environmental catastrophes}

The full scale of possible rapid environmental changes has not been recorded in the short period covered by the instrumental record (DeMenocal 2001; Weiss and Bradley, 2001). Therefore it is essential to turn to historical and even geological and archaeological archives, which span a much longer timescale. In some cases of robust dating or duration control, these archives may serve as adequate surrogates for the instrumental record. 


\subsection{Hand of God and first scientific observations}

Ancient societies saw the hand of God in the occurrence of environmental catastrophes that appeared unintelligible and, therefore, to have been caused by supernatural forces. However by the end of the Archaic Period (800-500 yr $\mathrm{BC}$ ), philosophers already were separating the forces of nature from the forces of a superpower; these forces became the subject of scientific observation. The philosophers of the Milesian school (city of Miletus, western Turkey) in the sixth century BC (Mullen, 1998) laid down the foundation of modern science by searching for common physical laws.

\subsection{Documentary evidence}

In Europe, the instrumental record often is considered to have begun by $\mathrm{C}$. AD 1850. Before that time, very good scientific records were kept in weather diaries in continental Europe as far back as C. AD 1500 (Pfister and Wanner, 2002). In China, documentary evidence (direct or indirect) dates back several thousands years (Pfister and Wanner, 2002; Qian et al., 2003). Recent initiatives have allowed historians to work with geologists to understand and complement ancient records (CLEMENS project of the Agenzia per la Protezione dell'Ambiente e per i servizi Technici, Italy).

2.3 Challenge of multidisciplinarity for improved reliability, dating and duration estimates

Intertwining hard sciences, such as geology, with soft social/human sciences, such as history and sociology, commonly still presents great difficulties.

Researchers representing the hard and soft sciences neither use the same investigative techniques, approaches and vocabularies, nor attend the same conferences and meetings. However, it is crucial that scientists from both areas work together as the field of environmental catastrophe research allies both the physical and the social arenas.

\subsubsection{Reliability levels of historical and geological data}

Sources of data should be evaluated, controlled and used to the extent applicable. An event may be documented through various types of data: religious texts (e.g. the Bible), collection of naïve stories (e.g. the Icelandic sagas of twelfth to thirteenth centuries) or instrumental records (e. g. the Roda's Nilometer). These sources of data were not compiled for the same purpose and are not of the same quality. The role of historians is to analyse these sources and to establish appropriate levels of credibility. The same process occurs with the numerous proxies used in geology, including palaeoclimatology. Scientists must use extra care when considering data of differing levels of certainty; for example, pollen does not record past climate, as do stable isotopes, with each proxy having its own merits and limits.

\subsubsection{Dating environmental changes}

If we are to reconstruct and correlate events of global scales, strict chronological requirements must be imposed. Indeed, one of the many factors necessary to establish causation securely is the close temporal succession of cause (hazard) and consequence (disaster).

Most historical documents are reliable to the year or even to the day (Guidoboni et al., 1994). Radiocarbon dating of terrestrial matter, such as 
seeds or wood, often provides less than fifty years precision, whereas radiocarbon dating of geomorphological features such a shoreline feature in carbonate-rich sediment, often is less precise than several centuries (sands and blocks moved by a tsunami) (Scheffers and Kelletat, 2005). One of the most commonly used dating techniques - radiocarbon - is often poorly understood and used. The reliability of each date should be examined and treated accordingly.

Baillie (1991) emphasizes that abrupt or "point" events tend to be smeared by radiocarbon dating. Thus, radiocarbon effectively conceals abrupt events. The converse case occurs when precisely dated events, for example abrupt environmental downturns deduced from tree-rings, tend to "suck in" proximate but poorly dated evidence. Events may then be turned into periods (Baillie, 1991).

\subsubsection{Time resolution of proxies}

The last decades of scientific investigation have shown that a significant range of geological proxies can provide yearly resolution records: ice cores, coral reefs, speleothems, laminated lake and marine sediment and tree-rings are the obvious proxies. Other proxies still may provide sequences at a resolution high enough to highlight brief phenomena. Geologists working on Holocene catastrophes have therefore the potential to reach a time resolution directly relevant to societies or even less (such as that of a life time or less).

\subsection{Environmental determinism}

The concept of environmental determinism has in turn been used and rejected. The emphasis now is on nature placing constraints on human endeavour: a delimiter rather than a prescriptive agent (Coombes and Barber, 2005). However, recent re-analyses of the collapses of many ancient civilisation recently have highlighted the major roles played by rapid and catastrophic environmental changes in their final demise, such as in the Old Kingdom in Egypt in 2200 cal. yr BC (Hassan, 1997), the Harappans of the Indus Valley (c. 2200 cal. yr BC), the Mayas (AD 900), the Tiwanaku (c. AD 1100) and the Mesopotamians (c. 2200 cal. yr BC) (DeMenocal 2001; Orlove, 2005). Many ancient, as well as recent, political crises seem to have emerged from pressure exerted on people by environmental stresses. Environmental determinism is seen again as an important basis for explaining the fall (Weiss and Bradley, 2001) and even the rise (Brooks, 2006) of past civilisations and societies.

Another reason to resurrect environmental determinism is linked to the quest for understanding natural phenomena in order to prepare better for their next occurrence. The palaeosciences aim when possible to establish the time when some natural hazards will recur, for example earthquakes and hurricanes, to improve predictive models and grasp the full range of environmental change.

\subsection{How large were environmental catastrophes in the Holocene?}

According to Coombes and Barber (2005), empirical evidence does not exist indicating that world or hemispheric catastrophes with civilisation collapse occurred in the Holocene; nonetheless, it still may be possible to uncover catastrophes that occurred during this period. Regarding major environmental 
catastrophes, only a fraction has caused societal collapse. In brief, the number of global catastrophes is smaller than we may think, but the number of major catastrophes is probably higher than is known.

Coombes and Barber (2005) only recognise two widespread cultural declines that were linked to climatic deteriorations, at $2200 \mathrm{cal}$. yr BC and at $850 \mathrm{cal}$. yr BC. In the case of 2200 cal. yr BC, the event was highlighted first by the sudden Akkadian collapse (empire extending from the headwaters of the Tigris and Euphrates Rivers to the Persian Gulf) due to drought. Synchronous collapses elsewhere in the world were discovered (Weiss and Bradley, 2001). In the case of 850 cal. yr BC (van Geel et al., 2004; 2006), shifts in settlement patterns in Western Europe have been assigned to the change to cooler and wetter conditions at the Sub-boreal/Sub-atlantic transition (Late Bronze Age). A global climatic change, with negative or positive impact on populations depending on local conditions, has been attributed to altered production of ${ }^{14} \mathrm{C}$ in the atmosphere at that time. Around AD 500, a retreat of agriculture is seen clearly both in Northern Europe and the Mediterranean Basin (Berglund, 2003; Issar, 2004). This decline occurred during the Dark Ages (also known as the Great Migration period, or the early Middle Ages) connecting cooling in the Atlantic Ocean in the north with a drought, perhaps due to a shift of the Intertropical Convergence Zone in the south.

\section{Relevance to modern societies and recovery}

\subsection{Why is it relevant to look at ancient societies?}

Some say that modern societies are quite different from ancient societies: after all, technology now makes it possible to resist natural hazards more effectively (Torrence, 2002). We even are able to predict the future with General Circulation Models, as well as anticipate where population growth will be the highest (Weiss and Bradley, 2001).

First, the world population is larger than ever and growing exponentially. Hence, with more people at risk, a hazard can become a disaster more readily. Although some areas may benefit from hyper-complex technologies, other areas, by far the largest segments, will remain marginal and fragile. The population expansion itself leads to colonisation of fragile environments that are more susceptible to natural hazards.

Second, societies are complex. Behaviours are more coded, hence causing humans to demonstrate less flexibility (Torrence, 2002). It would be unthinkable to displace populations in North America and Australia where relocation policies have caused immense problems in the past. In addition, complexity of laws regulating human interactions is increasing continuously. Third, today's societies rely more on constructed environments (Torrence, 2002). We often have more possessions that we want to protect. Societies with people fixed in cities (e.g. New Orleans) are less resilient than rural societies that can move more easily.

\subsection{Causes of failure to respond and to learn}

Diamond (2005) has proposed four reasons why societies fail to respond and learn from environmental catastrophes. Incorrect decisions may be made because the affected group has failed to a) anticipate the problem before it actually occurred, b) perceive a problem when it actually occurred, c) try to 
solve the problem and finally d) successfully solve the problem. This author also provides numerous examples under each category. The most interesting reason for failure is the purposeful refusal to solve a problem. This refusal may take hold for the following reasons: the group that perceives the problem belongs to a different political party, the present situation serves the elite, a warning (eruption evacuation) has been given too often thus desensitising the society to the potential threat, psychological denial (people living at the foot of a dam) and governmental emergency plans that have been set up for fixed durations (Diamond, 2005).

Fires devastated the city of San Francisco after the earthquake of 1906 . The need to begin rebuilding the city was urgent. In order to attract investment, the mayor downplayed the role of the earthquake, even removing the fault from geological maps and official photos and paintings in order to focus on the fire and thereby fabricate a different social memory. Fire also had devastated other cities and therefore was considered an acceptable rationale to rebuild by potential investors (UK Channel 4, 2006).

Another example of failure to learn from environmental catastrophes can be seen in the responses to strict anti-seismic building regulations passed by both Japan and Turkey, two highly seismic countries. These two populations have not been sensitised in the same way. For example, the Turkish people are not checking implementation of anti-seismic laws during rebuilding and thus the regulations too often are not being applied. Typically, young families setting up new homes in Istanbul are not including these regulations amongst the criteria used in selecting the ideal locations for their new homes.

\subsection{Recovery from catastrophic environmental events}

How quickly (and by what means) are ecosystems and civilisations able to recover from catastrophic environmental events? Recovery could mean returning to pre-catastrophic conditions, but also it could mean bringing the post-disaster condition to an acceptable level. In any case, recovery should attempt to reach a condition that will enable the society to become more resilient to a renewed hazard.

Here it is interesting to address the question not only of recovery but also of learning from a catastrophic event. Four potential cases may be envisaged to illuminate the questions: (a) A natural hazard has occurred, but it does not cause a disaster. In this case, only a few people, such as a remote island community, are aware of the natural hazard. There are no sensors in the area, and the event hardly enters the instrumental record. (b) Human losses result from the event, and afterwards, people try to return to pre-catastrophe conditions. (c) Human losses result from the event, but people recover to improved conditions in order to minimise further impact. (d) Complete collapse results from the event. Hardly anyone survives (or hardly any of the educated people) to tell the story to their descendents. Out of these four cases, only one represents a society that learned from the event: case (c), which represents a society that attempted to find a new balance, better adapted to the changing environment.

\subsection{Do we learn?}

It may be argued as a general principle that when intervals between events are long, people tend to forget the details unless a written record or an oral 
tradition are actively maintained alive. To the contrary, when intervals are short, memory is transmitted amongst generations, making it is easier to learn from experience and thus be prepared. The following paragraphs present exceptions to this general principle, as well as several success stories, too. Following the 2004 tsunami in the Indian Ocean (>87,000 deaths), the 2005 hurricane Katrina in New Orleans (>1300 deaths) and the lesser known 2005 Hurricane Stan in Guatemala ( $>1500$ deaths), the aim of international and local aid organisations and local communities was to begin reconstructing buildings rapidly, mostly in the exact same locations.

The 1999 Turkey earthquake required extensive rebuilding, and amazingly some structures were rebuilt in exactly the same locations as the previously destroyed buildings. However, it is well established that the North Anatolian Fault will move again within a lifetime. Hotel Sapanca, built along the shore of Lake Sapanca, was destroyed by shaking and subsidence in the lake which lies over the North Anatolian Fault. The hotel has been rebuilt through private funding six years after the catastrophe, in fact a few meters away from the previous location.

Actual cases where environmental collapse has been avoided are difficult to highlight because of the non-linearity inherent in the link between hazard and disaster. However, success stories of hazard mitigation fortunately are beginning to increase. For example, the rebuilding of a dam upstream of Los Angeles after the 1971 San Fernando earthquake followed very strict antiseismic regulations, thus a disaster was avoided when the 1994 Northridge earthquake occurred (USGS, 2006). The 1971 eruption of the Mount Pinatubo Volcano could have killed more than ten thousand people if adequate monitoring had not allowed the timely evacuation of the local population (USGS, 2006). Another example of successful recovery from a natural disaster includes the 1953 flood in the Netherlands and the building of a network of protective dams. Most Dutch people live below sea level regardless of social status, and consequently society at all levels is concerned for the well being of the total population (Diamond, 2005).

\section{Future}

Solutions in the past may have been created to foster myths to explain environmental catastrophes and taboos in order to restrict or enforce tribal law. These myths and taboos often were originated by the spiritual leader and put in place by the tribal leader. Conversely, in modern times, we look for solutions based on science and technology, education at all levels, and perhaps deep personal change

\subsection{Scientific observation and understanding}

Geoscientists increasingly are participating in environmental geomonitoring, as geological changes are occurring not only at the very slow scale of millions of years, but also at the very rapid scale of decades if not months. Because the latter is often underrated, the International Union of Geological Sciences (IUGS) has initiated the project GEOINDICATORS, which aims to assess rapid environmental changes in Earth systems (GEOIN, 2006). Intensive environmental monitoring (not only of hurricanes, earthquakes and volcanoes, but also of beach erosion, salinisation of the water table and karst activity) is 
necessary to observe how changes are occurring in order to first react quickly, and second to understand and improve predictive capacity.

Depending on the recurrence interval of an event and available funding, we should either follow the education and warning system line (low frequency: e. g. the tsunami warning network in the eastern Mediterranean Sea) or the more costly infrastructure line (high frequency; e g. the Dutch dams built to prevent flooding after the major flood of 1953). In parts of the world that still have low population densities, creation of nature parks with limited habitations could be a solution to limit the impact of disasters by reducing concentrations of at-risk populations.

Sri Lanka was directly affected by the 2004 Indian Ocean tsunami. The Coast Conservation Department very wisely has proposed enactment of new laws forbidding building along the coast within a strip 100 to 200 m wide. However the opposition political party has suggested another solution based on improved infrastructure. However, there is no space for coastal inhabitants to relocate inland because the area is already densely settled, and tsunamiresistant infrastructure would be too expensive. Consequently, even though various improvements have been proposed, in the end, people will have to rely primarily on a warning system.

\subsection{Education}

As previously stated, education is crucial and should be implemented concurrently at three different levels: communication among scientists of varying disciplines and creation of a bridge of quality between scientists and the media, as well as education for all people.

\subsubsection{Communications among scientific disciplines}

Breaking down the usual barriers between scientific communities in order to forge a new mix of people is a challenge. With the demands of academic life, scientists often give priority to meetings focusing on their own specialities. Scientists must make a special effort to attend thematic and multidisciplinary conferences outside their own specialities.

Geology, a science that conventionally addresses hard rocks, increasingly is turning to recent times and high-time resolution, such as a human/societal generation (c. 30 years) or less. In addition, archaeology, traditionally an "Art and Humanities" subject increasingly is becoming more scientific and turning to natural and earth sciences. A new discipline is emerging at the limits of those that traditionally did not regularly intermingle. We propose to call this new synergy "the science of environmental catastrophes."

\subsubsection{Creation of a bridge of quality between scientists and the public domain}

This level of education is more difficult to achieve than the preceding level. On one hand, scientists are under increasing pressure to publish a maximum number of papers and to garner maximum grant awards. Thus, they believe that activities connected to public relations and distribution of information to a wider audience (media and end users) are not valued by their universities and supporting institutions. Scientists, who dedicate considerable time to the media, often are poorly considered by their peers because of the compromise they must make with scientific rigour in order to disseminate scientific information via the media. On the other hand, media personnel tend to 
oversimplify scientific facts and inflate events to sustain public attention. Most media personnel and end-users primarily rely on information quickly gathered from short interviews or briefs prepared for them by governmental offices.

Few have the time to read scientific literature.

Hence, we must train a new category of people capable of understanding and translating core scientific literature, within the limitations of scientific data, for the wider public audience, making it comprehensible by the average citizen. Therefore, a bridge of quality for transferring technical information from scientific journals to the public domain must be nurtured.

\subsubsection{Education of people to mitigate the impacts of a environmental catastrophe}

Educating people from the youngest to the oldest is a task for each government. Since 1994, Canada and the United States have conducted a collaboration regarding warning guidance, mitigation and assessment of tsunami hazards. Signs have been installed along the coast, and an education programme has been organised by the National Tsunami Hazard Mitigation Program - a partnership among the U.S. states of Alaska, California, Hawaii, Oregon, and Washington and the National Oceanic and Atmospheric Administration, Federal Emergency Management Agency, and U.S. Geological Survey (The National Tsunami Hazard Mitigation Program, 2005). The Indian Ocean Tsunami Warning and Mitigation System has not realised the same success, since some countries have been reticent to share data that may have military implications.

For the Indian Ocean tsunami, two examples where knowledge transmission systems proved immensely useful in saving lives can be mentioned. A British schoolgirl on holiday in Thailand remembered her geography lesson and warned her family and fellow tourists, thus saving them. Many of the Andaman and Nicobar tribes, still living as hunters-gatherers on islands with some relief, withdrew to high ground and so escaped the worth of the tsunami. Traditional knowledge allowed tribesmen on these islands and also on Simeulue Island (west of Sumatra) to forecast the consequences of the odd ocean behaviour and earthquake.

\section{$\underline{4.3 \text { Are we ready to drop some core societal values? }}$}

When methods, such as those identified in the preceding paragraph fail, we must turn to a more drastic approach. As suggested by Diamond (2005), a society then must be ready to drop some core values such as religious beliefs, freedom of expression, equal opportunity, sources of energy or income, ideal living or business location, and hierarchy. A good example of this concept is the flooding of New Orleans. If the US people were willing to drop certain core values, they might consider rebuilding the city on higher ground. In the short term, an organised movement of the people would be difficult to accept but beneficial in the long term (Orlove, 2005). Migration has been a solution in the past to crises brought on by climatic change: US dust bowl, Classic Maya collapse, and Viking settlements in Greenland (Orlove, 2005).

In some countries because of past cases of forced population displacement, for example, in Canada and the United States involving minority groups, the idea of displacing a segment of the population cannot be considered without 
evoking a great outcry! However, uncontrolled movements of populations occur all the time: for example, from the south to the north between Mexico and the United States, as well as between North Africa and Europe, for example on makeshift boats via Gibraltar or via the strait of Sicily. In both cases, this migration has been motivated by poorer economies in the southern areas, often exacerbated by climatic change and other rapid environmental changes. The numbers of people displaced within and out of a country owing to natural events is on the increase, because the people have to re-settle and often into vulnerable areas, such at the margins of cities (e.g. Mexico city) and in camps (e.g. Tristan da Cunha) (Lonergan et al., 1999).

\subsection{New forces driving human adaptability}

Democratic political parties and green movements nowadays are not able to convince people of deep environmental changes. Only various radical factions currently are convincing or forcing people to change. Regardless, few political powers place environmental considerations high on their agendas. A successful example of top-down force used to modify practices affecting the environment occurred in Japan when the Tokugawa shogunate (seventeen century AD) managed to fight deforestation of their island by imposing regulations on farmers and modifying building techniques (Diamond, 2005). Forces that cause people to leave their homes willingly and rebuild elsewhere include prospects for better jobs and lack of insurance coverage to protect property and personal belongings. The insurance sector is the world's largest industry and often acts as the messenger of economic impact resulting from environmental disasters through the terms and prices of their policies (Mills, 2005). Although the influence exerted by insurance companies remains limited in developing countries, pools for insurance coverage are beginning to be set up in countries such as Mexico, Turkey and Ethiopia (Linnerooth-Bayer et al., 2005). However, it is quite different in developed countries where people have become accustomed to relying heavily on insurance for protection against an ever-increasing range of environmental hazards. Typically there is a dramatic underestimation of exposure by insurance companies, the number of claims increases rapidly and the policies cost is increasing (Mills, 2005).

\subsection{The science of environmental catastrophes versus catastrophism}

When the word catastrophe is presented, there is often the danger of falling into catastrophism, an area where apocalypse predictors are never far behind (Peiser, 2003). Catastrophism is a concept that quickly takes hold due to an abundance of media outlets (Web pages, books, videos, public talks) whose content often is qualified inappropriately as scientific.

The science of environmental catastrophes should be based on strong scientific methodology, which includes fieldwork, laboratory analyses, experimentation, collection of reproducible data, comparisons, and hypotheses tested and peer-reviewed. In brief, scientists working in the new discipline should use caution vigilantly to avoid an imperceptible slide from facts to "not impossible" links, finding the right position between doom predictors and scientists who are too cautious. 


\section{Conclusion}

We must remember that natural events embody tremendous power to cause environmental catastrophes, and this power is as great as the power that humans possess nowadays to damage their environments. Although the number of natural hazards is increasing somewhat, especially hydrometeorological events, it is evident that the number of disasters will rise dramatically in the near future. Indeed colonisation of marginal environments caused by population pressures is placing the world at greater risk from natural hazards and catastrophes than ever before. Finally, this new field of geosciences is both challenging and fascinating by its relevance to the world where we live. To survive, we must learn from the past, adapt to environmental changes, and modify our life styles in front of a darkening nature.

\section{Acknowledgements}

First, I would like to thank all those I have exchanged ideas over the last years through the Dark Nature project and predecessor projects, especially I. Stewart, T. Berger, K. Arpe, N. Kazancı and M. Williams. The academic sponsors of the conference were ICSU DN via IUGS, IGCP 490, INQUA, PAGES, The British Academy, IUGS-Geoindicators and IUGS-SOTSPI, as well as Brunel University. A visiting faculty scholarship from the Desert Research Institute (Nevada System of Higher Education) allowed me time to write this paper. Thank you to L. Wable (DRI) for the illustration and J. Lease (DRI) for the editing.

\section{References}

Ambraseys, N., Finkel, C., 1991. Long-term seismicity of Istanbul and the Marmara Sea region. Terra Nova (3), 527-539.

Baillie, M.G.L., 1991. Suck in and smear - two related chronological problems for the 90s. Journal of Theoretical Archaeology (2), 12-16.

Berger, A. R., 2006. Abrupt geological changes: causes, effects and public issues. Quaternary International. In press.

Berglund, B. E., 2003. Human impact and climate changes - synchronous events and a causal link? Quaternary International (105), 7-12.

Brooks ,N., 2006. Cultural responses to aridity in the Middle Holocene and increased social complexity. Quaternary International. In press.

Coombes, P., Barber, K., 2005. Environmental determinism in Holocene research: causality or coincidence? Area (37.3), 303-311.

DeMenocal, P., 2001. Cultural Responses to Climate Change During the Late Holocene. Science (292), 667-673.

Diamond, J., 2005. Collapse: How Societies Choose to Fail or Succeed. Viking Press, New York, pp 575.

GEOIN, 2006. www.lgt.It/geoin/

Guidoboni, E, Comastri, A., Traina, G., 1994. Catalogue of ancient earthquakes in the Mediterranean area up to the 10th century, ING-SGA, Bologna, 504 pp.

Hassan, F., 1997. Nile Floods and Political Disorder in Early Egypt. In: Dalfes, H. N., Kukla, G., Weiss, H. (Ed.), Third Millennium BC Climate Change and Old World Collapse. Springer, New York, I (49), 1-23.

Heim, C., Nowaczyk, N., Negendank, J., Leroy, S., Ben-Avraham, Z., 1997. 
Middle-East desertification: evidence from the Dead Sea.

Naturwissenschaften: 84 (9), 398-401.

Hunt, T., Lipo, C., 2006. Late Colonization of Easter Island. Science.

Accepted on February 21, 2006.

ICCU, 2005. Science and natural hazards.

http://www.icsu.org/6_memberzone/GA_documentation/9_Hazards.pdf

ICSU, 2006. ICSU: Dark Nature - Rapid natural change and human responses. www.mun.ca/canqua/ICSU-DN/

IGCP 490, 2006. IGCP490 - The role of Holocene environmental catastrophes in human history. www.mun.ca/canqua/igcp490/

Issar, A. S., 2004. Climate Change - Environment And Civilization In The Middle East. Springer Verlag 250 pp.

Leroy, S., Kazancı, N., Ileri, Ö., Kibar, M., Emre, O., McGee, E., Griffiths, H. I., 2002. Abrupt environmental changes within a late Holocene lacustrine sequence south of the Marmara Sea (Lake Manyas, N-W Turkey): possible links with seismic events. Marine Geology 190 (1-2), 531-552.

Leroy, S., Costa, P. (ed.), 2004. "Environmental catastrophes in Mauritania, the desert and the coast", volume of abstract and field guide. ICSU Dark Nature-IGCP490, first joint meeting 4-18 Jan. 2004 Mauritania. 198 pp. http://atlas-conferences.com/cgi-bin/abstract/camu-01

Leroy, S., Stewart, I. (Ed.), 2002. "Environmental catastrophes and recovery in the Holocene", Volume of abstracts, conference held at Brunel University, West London, 28 Aug. - 2 Sept. 2002. 90 pp. http://atlasconferences.com/c/a/i/q/01.htm

Leroy, S., Jousse, H., Cremaschi, M., 2006a. Dark Nature: Impact of rapid environmental changes on humans and ecosystems. Quaternary International 150.

Leroy, S., Jousse, H., Cremaschi, M., 2006b. Dark Nature: Responses of humans and ecosystems to rapid environmental changes. Quaternary International. 151.

Linnerooth-Bayer, J., Mechler, R., Pflug, G., 2005. Refocusing disaster aid. Science (309), 1044-1046.

Lonergan, S., et al., 1999. Global Environmental Change and Human Security: Science Plan IHDP Report Series No. 11, Bonn, Germany. 60 pp.

Michetti, A.M., Aligi Pasquare, F., Haldorsen, S., Leroy, S., 2005. Final Meeting, Dark Nature - Rapid Natural Change and Human Responses, September 6-10, 2005, Villa Olmo, Como, Italy. http://atlasconferences.com/cgi-bin/abstract/caqy-01

Mills, E., 2005. Insurance in a climate of change. Science (309), 1040-1044.

Mullen, W., 1998. The agenda of the Milesian school: the post-catastrophic paradigm shift in ancient Greece. In: Peiser, B. J., Palmer, T., Bailey, M. E. (Ed.), British Archaeological Reports 728 Natural Catastrophes During Bronze Age Civilisations: Archaeological, geological, astronomical and cultural perspectives.

The National Tsunami Hazard Mitigation Program, 2005. www.pmel.noaa.gov/tsunami-hazard/

Orlove, B., 2005. Human adaptation to climate change; a review of three historical cases and some general perspectives. Environmental science 7 policy: in press. 
Peiser, B., 2003. Climate change and civilisation collapse. In: Okonski, K. (Ed.), Adapt or die: the science, politics and economies of climate change. London, Profile Books, pp. 191-201.

Pfister, C., Wanner, H., 2002. Editorial to documentary evidence. PAGES newsletter 10 (3), 2.

Piovano E., Villalba R. and Leroy, S. (eds), in prep.- "Holocene environmental catastrophes in South America: from the lowlands to the Andes" special issue of Quaternary International

Qian, W., Hu, Q., Zhu, Y., Lee, D.-K., 2003. Centennial-scale dry-wet variations in East Asia. Climate Dynamics (21), 77-89.

Rampino, M., 2002. Supereruptions as a threat to civilizations on Earth-like planets. Icarus (156), 562-569.

Scheffers, A., Kelletat, D., 2005. Tsunami relics on the coastal landscape west of Lisbon, Portugal. Science of Tsunami Hazards 23 (1), 3-16.

Sparks S. \& Self S. et al., 2005. Super-eruptions: global effects and future threats. Report of a Geological Society of London Working Group (2nd (print) Edn.).

Stiros, S. C., 2001. The AD 365 Crete earthquake and possible seismic clustering: a review of historical and archaeological data: Journal of Structural Geology (23), 545-562.

Torrence, R., 2002. What makes a disaster? A long-term view of volcanic eruptions and human responses in Papua New Guinea. In: Torrence R., Grattan, J. (Eds.), Natural Disasters and Culture Change. Routledge, London, pp. 292-310.

Torrence, R., Grattan, J., 2002. The archaeology of disasters: past and future trends. In: Torrence R., Grattan, J. (Eds.), Natural Disasters and Culture Change. Routledge, London, pp. 1-18.

UK Channel 4 documentary, Jan. 2006, The San Francisco earthquake and fire of 1906 . www.channel4.com/history/microsites/H/history/cd/cities04.html.

USGS, 2006. www.usgs.gov/sndr/success.html

van Geel, B., Bokovenko, N.A., Burova, N.D., Chugunov, K.V., Dergachev, V.A., Dirksen, V.G., Kulkova, M., Nagler, A., Parzinger, H., van der Plicht, J., Vasiliev, S.S., Zaitseva, G.I., 2004. Climate change and the expansion of the Scythian culture after $850 \mathrm{BC}$, a hypothesis. Journal of Archaeological Science (31), 1735-1742.

van Geel, B., Buurman, J., Waterbolk, H.T., 1996. Archaeological and palaeoecological indications for an abrupt climate change in The Netherlands and evidence for climatological teleconnections around 2650 BP. Journal of Quaternary Science (11), 451-460.

Weiss, H., Bradley R. S., 2001. What drives societal collapse? Science (291), 609-610. 